\title{
The Relationship between Mobile Phone Addiction and Depression and Hopelessness among High School Students in Divandareh city in 2018
}

\section{Karo Servatyari ${ }^{1 *}$, Pooya Valizadeh Ardalan ${ }^{2}$, Shima Yazdanpanah ${ }^{3}$, Hero Yazdanpanah ${ }^{1}$ and Milad Parkalian ${ }^{4}$}

${ }^{1}$ Medical Student, Student Research Committee, Kurdistan University of Medical Sciences, Sanandaj, Iran

${ }^{2}$ Bachelor of Science in Medical Laboratory Sciences, Student Research Committee, Kurdistan University of Medical Sciences, Sanandaj, Iran ${ }^{3}$ Student of Primary Education, Faculty of Pardis Bentolhoda Sadr Kurdistan, Farhangian University, Sanandaj, Iran

${ }^{4}$ Master of science student in general psychology, Bu-Ali Sina University, Hamedan, Iran

*Corresponding Author: Karo Servatyari, Medical Student, Student Research Committee, Kurdistan University of Medical Sciences, Sanandaj, Iran.

Received: September 04, 2019; Published: September 13, 2019

DOI: $10.31080 /$ ASMS.2019.03.0408

\begin{abstract}
Background and Purpose: Overuse of the mobile phone, like any phenomenon related to other technologies, also has its disadvantages and Causes personal, social, and psychological problems such as depression, hopelessness, anxiety, stress, sleep disorders, and social isolation.

The purpose of this study was to determine the relationship between mobile phone addiction and depression and hopelessness and its prevalence among high school students in Divandareh city.

Method: This is a cross-sectional study. Statistical population included high school students in Divandareh city (Kurdistan Province, Iran) and sample size according to Cochran formula was estimated 384 students. Data was collected using a demographic questionnaire and a standard mobile addiction questionnaire, Beck Depression and Beck Hopelessness Questionnaire. Data was entered into SPSS-21 software and analyzed by t-test, chi-square and ANOVA.

Findings: In the present study, out of 370 high school students in Divandareh city, 54\% (198 students) were boys and $46 \%$ (172 students) were girls. According to the chi-square test, there was a significant relationship between depression and hopelessness with mobile phone addiction $(\mathrm{P}<0.001)$. There was also a significant relationship between sex and mobile phone addiction $(\mathrm{P}=0.004)$. On the other hand, according to ANOVA test, no significant relationship was found between age and mobile phone addiction ( $\mathrm{P}=0.601$ ). Conclusion: The results of this study show that traumatic and excessive use of mobile phones is a potential risk factor for mental disorders in students and such disorders are in turn an effective factor in decreasing students' academic performance.
\end{abstract}

Keywords: Mobile Phone Addiction; Depression; Hopelessness; Students; High School

\section{Introduction}

Today, mobile phones play a key role in the communication of different countries and it provides a wide range of possibilities for its users [1]. China's mobile usage as the world's most populous country in 2016 reached over 695 million users, representing 10\% annual growth [2]. Overuse of cell phones, like any other technology-related phenomenon, also has its disadvantages [3]. Many researchers believe that overuse of the cell phone in the minds and nerves of users causes a form of addiction that is just as destructive as drug addiction, alcohol, eating much, computer games and the Internet [4]. Mobile phone addiction is a widespread problem among adults around the world [5]. Addiction to his cell phone shows up while doing other things including study, driving, cycling and even sleeping [6]. International research shows that about $6 \%$ of mobile phone users are addicted to it [7]. In Iran, the prevalence of mobile phone addiction has been relatively high, for example, 
this percentage has reached $10 \%$ among Tehran University students [8]. Overuse of the cell phone can lead to personal, social and psychological problems such as depression, anxiety, stress, sleep disturbance and social isolation [9,10]. Using a mobile phone can also affect students' academic performance and reduce their academic performance or decrease their focus in the classroom [11]. As mentioned, depression is one of the consequences of cell phone addiction [12].

Depression is one of the most common mental disorders in the general population and may include sadness, loss of interest or pleasure, guilt or self-esteem, sleep or appetite impairment, fatigue, and will most likely lead to suicide. The World Health Organization (WHO) estimates that there are 322 million people with depression worldwide, with nearly half of them living in Southeast Asia and the western Pacific [13]. In 2015, the WHO estimated the prevalence of depression to be $4.4 \%$, which is higher in women (5.1\%) than men (3.6\%) [13]. In Iran, ratios between $4.2 \%$ and $37 \%$ have been reported in various studies for depression [14]. It is estimated that about 10 percent of people have depression at least once in their lives. It can occur in any person, regardless of race, class or social status [15]. Every person in their lifetime may have depression that can have various symptoms such as feelings of worthlessness, constant sadness, thought disorder, difficulty concentrating and sleep disturbance that can impair the health of the body and soul Risk [16]. Depression is a debilitating factor in the world, with about $50 \%$ of it occurring in the workplace. Around 121 million people worldwide have the disease, and in Iran, the percentage is between 4.2 and 37 for the general population [14].

Beck says hopelessness is a major cause of depression, which can have many consequences for the person, including weakening the will, intolerance to various situations, behavioral problems, substance abuse, and an increased risk of suicide. The negative things in life, such as unemployment and illness, can be frustrating. Today, the increasing number of psychological problems and conflicts have increased the prevalence of despair that has made this issue more important than ever before $[17,18]$.

Research has shown that depressed people are more likely to fill their leisure time with a mobile phone [19]. In fact, depressed people use cell phones as a way to escape real problems, feelings of boredom, guilt, loneliness, anxiety and depression [20]. Given the increasing prevalence of mobile phone addiction in high school students and the lack of coherent work, we found it important to research this area that can be made available to organizations and institutions to help control mobile phone addiction. The purpose of this study was to determine the relationship between mobile phone addiction, depression and hopelessness and its prevalence among high school students in Divandareh city in 2018.

\section{Materials and Methods}

This study is a cross-sectional study. The statistical population consisted of all high school students (16-18 years) in Divandareh city (Kurdistan Province -Iran Country) in 2018. The sampling method was stratified and randomly selected within each class. The sample size was estimated to be 384 according to the Cochran formula ( $\mathrm{P}=0.5$ and $\mathrm{d}=0.05)$. Inclusion criteria included informed consent and satisfaction as well as completedi, accurate and accurate questionnaires, and exclusion criteria included unwillingness to complete or not completing the questionnaires. After obtaining permission from the General Department of Education of the Kurdistan Province and with the agreement of the school principals, the objectives of the study are explained to the students of each selected school. After obtaining informed consent from all students to complete the information contained in the questionnaire, they were invited to participate in the study to obtain their consent to participate in the study and also to retain all information related to them. Trained interviewers attend schools in accordance with a pre-determined schedule and in one of the classrooms read the questionnaire questions to the students and ask them to mark the answer in the questionnaire, one of the questioners was present in the classroom to answer any questions the students might have.

\section{Tool}

Data were collected using a demographic questionnaire (including age, sex, Grade Point Average) and 3 standard mobile addiction questionnaires and Beck Depression and Hopelessness Questionnaire.

Mobile Addiction Questionnaire was developed by Rider (2014) with 3 components and 13 items. The components of this questionnaire include three areas of de-creativity, desire and loneliness. The questionnaire consisted of 13 questions, rated on a 5-point Likert scale ( 0 to 4 ), with a high of 52 and a low of zero (0). A total score of less than 13 indicates of low addiction (cohesion), a score 
of 13-26 means moderate addiction a score above 26 indicates a high level of addiction. Karim Savari, estimated the reliability of the questionnaire to be 0.87 for the whole questionnaire, 0.78 for the de-creativity factor, 0.76 for the desire factor, and 0.84 for the loneliness factor. Validity of the questionnaire was confirmed by confirmatory factor analysis [21].

Beck Depression Inventory: Beck Depression Inventory the Beck Depression Inventory was designed in the 1970s to determine the presence or absence of depression and its severity in youth and adolescents. Beck Depression Inventory assesses severely the state of depression in all psychiatric disorders and has a good application in evaluating psychotherapy and the effect of different treatments on the patient. The questionnaire contains 21 sentences. The components of the questionnaire include the following 21 components:

- Sadness, skepticism, past failure, dislike, guilt, punishment, dislike, self-criticism, suicidal thoughts or suicidal tendencies, crying, restlessness, Loss of interest, Indecision, Worthless, Loss of energy, Change in sleep pattern, Mobility, Change in appetite, Difficulty in focus, Fatigue or fatigue, Loss of sexual interest.

Questionnaire ratings are based on a four-point Likert scale ranging from strongly agree (3) to strongly disagree (0).

The analysis based on the score of the questionnaire is that the scores of each of the 21 scales should be aggregated. The minimum possible score will be 0 and the maximum is 63 .

- Score between 0 and 21: Depression is poor in this community.

- Score between 21 and 31: Depression is moderate in this population.

- Score above 31: Depression is strong in this community.

Fathi (2003), using this questionnaire in Iran, reported a Cronbach's alpha of $91 \%$ and a one-week retest of $94 \%$ [22].

Beck hopelessness questionnaire

The questionnaire consists of 20 questions designed to examine the three-dimensionality of one's hopelessness (one's sense of future, motivation or loss of motivation and expectations).
Beck (quoted by Bruin, 1997) cites despair as the nuclear sign of depression, pointing out that despair is both paralyzing and intolerable and a desire to escape a situation [23].

The questionnaire is a 20 -item scale that the individual will answer correctly or incorrectly by reading each item. This three-dimensional questionnaire measures one's hopelessness: one's sense of future, motivation, or loss of motivation and expectations. The questionnaire is designed for 16- to 80-year-olds with a score of 0 to 120 , with higher scores indicating greater frustration. To score a questionnaire, each item must be given a score of 0 or 1 (according to this questionnaire, 9 questions are based on incorrect answers and 11 questions are based on correct answers).

Next, the three sub-scales of this questionnaire should be extracted.

- If the questionnaire scores are between 0 and 3, the level of frustration in this population is minimal.

- If the questionnaire scores are between 4 and 8 , the level of frustration is mild.

- If the questionnaire scores are between 9 and 14, the level of disappointment is at a moderate level.

- If the questionnaire scores are between 15 and 20, the level of frustration is very high.

Adolescents have been used in various studies and its validity and reliability have been evaluated [24].

\section{Results}

In the present study, out of 370 high school students in Divandareh city, 54\% (198 students) were boys and 46\% (172 students) were girls. The mean and deviation of age was $16.8 \pm 0.716$.

Based on the results of the present study (Table 1), based on the t-test, a significant relationship was observed between sex and mobile phone addiction $(\mathrm{P}=0.004)$. On the other hand, according to ANOVA test, no significant relationship was found between age and mobile phone addiction $(\mathrm{P}=0.601)$. Other results of the present study based on Chi-square test showed a significant relationship between academic achievement and mobile phone addiction $(\mathrm{P}=0.017)$. 


\begin{tabular}{|l|l|c|c|c|c|c|}
\hline \multicolumn{2}{|l|}{} & Mild mobile addiction & Moderate mobile addiction & Severe mobile addiction & Total & P value \\
\hline \multirow{2}{*}{ Sex } & Male & $42(21.2 \%)$ & $86(43.4 \%)$ & $70(35.4 \%)$ & $198(100 \%)$ & $\mathrm{P}=0.004$ \\
\cline { 2 - 6 } & Female & $61(35.7 \%)$ & $52(30.4 \%)$ & $58(33.9 \%)$ & $171(100 \%)$ & \\
\hline \multirow{2}{*}{ Total } & $103(27.9 \%)$ & $138(37.4 \%)$ & $128(34.7 \%)$ & $369(100 \%)$ & \\
\hline \multirow{2}{*}{ GPA } & Bad & $31(23.1 \%)$ & $44(32.8 \%)$ & $59(44 \%)$ & $134(100 \%)$ & $\mathrm{P}=0.017$ \\
\cline { 2 - 6 } & Good & $72(30.6 \%)$ & $94(40 \%)$ & $69(29.4 \%)$ & $235(100 \%)$ & \\
\hline \multicolumn{2}{|l|}{ Total } & $103(27.9 \%)$ & $138(37.4 \%)$ & $128(34.7 \%)$ & $369(100 \%)$ & \\
\hline
\end{tabular}

Table 1: Relationship between mobile phone addiction, gender, and GPA among high school students in Divandareh city in 2018.

On the other hand, according to the Chi-square test (Table 2), there was a significant relationship between depression and mobile phone addiction $(\mathrm{P}<0.001)$.
Also according to Chi-square test (Table 3), there was a statistically significant relationship between hopelessness and mobile phone addiction $(\mathrm{P}<0.001)$.

\begin{tabular}{|l|l|c|c|c|c|}
\hline \multicolumn{2}{|c|}{} & \multicolumn{3}{|c|}{ Depression } & \multirow{2}{*}{ Total } \\
\cline { 3 - 6 } \multicolumn{2}{|c|}{} & Mild Depression & Moderate Depression & Severe Depression \\
\hline \multirow{2}{*}{ Mobile Addiction } & Mild Mobile Addiction & $92(89.3 \%)$ & $9(8.7 \%)$ & $2(1.9 \%)$ & $103(100 \%)$ \\
\cline { 2 - 6 } & Moderate Mobile Addiction & $102(73.9 \%)$ & $28(20.3 \%)$ & $8(5.8 \%)$ & $138(100 \%)$ \\
\cline { 2 - 6 } & Severe Mobile Addiction & $71(55.5 \%)$ & $42(32.8 \%)$ & $15(11.7 \%)$ & $128(100 \%)$ \\
\hline \multicolumn{2}{|l|}{ Total } & $265(71.8 \%)$ & $79(21.4 \%)$ & $25(6.8 \%)$ & $369(100 \%)$ \\
\hline
\end{tabular}

Table 2: Relationship between mobile phone addiction and depression among high school students in Divandareh city in 2018 (Chi-square test).

\begin{tabular}{|l|l|c|c|c|c|}
\hline \multicolumn{2}{|c|}{} & \multicolumn{3}{|c|}{ Hopelessness } & \multicolumn{2}{c|}{ Total } \\
\cline { 3 - 6 } \multicolumn{2}{|c|}{} & Mild Hopelessness & Moderate Hopelessness & Severe Hopelessness \\
\hline $\begin{array}{l}\text { Mobile } \\
\text { Addiction }\end{array}$ & Mild Mobile Addiction & $94(48.5 \%)$ & $8(7.8 \%)$ & $1(1 \%)$ & $103(100 \%)$ \\
\cline { 2 - 6 } & Moderate Mobile Addiction & $93(31.2 \%)$ & $33(23.9 \%)$ & $12(8.7 \%)$ & $138(100 \%)$ \\
\cline { 2 - 6 } & Severe Mobile Addiction & $89(6.6 \%)$ & $31(24.2 \%)$ & $128(100 \%)$ \\
\hline \multirow{2}{*}{ Total } & $276(34.4 \%)$ & $72(19.5 \%)$ & $21(5.7 \%)$ & $369(100 \%)$ \\
\hline
\end{tabular}

Table 3: Relationship between mobile phone addiction and hopelessness among high school students in Divandareh city in 2018 (Chi-square test).

\section{Discussion}

News shows mobile phone addiction in Divandarah city students as a relatively low-income city. According to the past research on high school students in the city, the severity of mental disorders, including depression and anxiety, was 17\%, which in turn was significant [25].

According to the chi-square test, there was a significant relationship between depression and mobile phone addiction
$(\mathrm{P}<0.001)$. According to this table, 44.5\% $(\mathrm{n}=57)$ of students with severe cell phone addiction had moderate to severe depression. So, depending on the amount of students' cell phone addiction and their depression, it can be concluded that the more students are dependent on their cell phone, the higher their depression rate will naturally be this was in line with the results of previous research, including Aljohara., et al. [5] and Višnjić., et al. [26], who conducted the study on Saudi and Serbian students, respectively. Based on the chi-square test and as can be seen in Table 1, there was a signifi- 
cant relationship between students' mobile phone addiction and gender $(\mathrm{P}=0.004)$. And among male students, $78.8 \%$ (156) of the male students had moderate to severe mobile addiction, compared with $64.3 \%$ for female students. These results are inconsistent with the results of previous studies that considered gender to be a mobile addiction [27] and with some results that did not show a significant relationship between gender and mobile phone addiction [28]. The reason for the difference in results may be due to different time and place of research in a way that in Divandareh city, due to the small population and traditional community, a particular behavioral pattern such as cell phone use is becoming more and more of an epidemic in the community. On the other hand, different factors such as the type of questionnaire and the research instrument and the socio-economic characteristics of the community will influence the outcome.

According to the results of this study, there was a significant inverse relationship between students' average score and mobile phone addiction $(\mathrm{P}=0.017)$. These results are in line with previous research findings $[29,30]$. Explaining this similarity, it can be said that unnecessary use of mobile phones by students leads to waste of time and excessive use of mobile phones reduces students' mental capacity and students have less time to study the same factor can lower academic performance. Although mobile internet can be an educational tool due to its high functionality, unfortunately students often logged in on unrelated sites and had less time to read than did their educational activities, leading to their academic and educational decline. Finally, it is noteworthy that increased use of cell phones during the day and night reduced the quality and quantity of sleep in children and these children were sleepy in the classroom, which in turn reduced the focus and efficiency of students in the classroom [31]. On the other hand, due to the relationship between mobile addiction with depression and hopelessness, and the relationship between depression and aggression in children, teaching the parenting style to parents and increasing the emotional relationship between children and parents can reduce cell phone addiction in children [32].

\section{Conclusion}

Many students are attracted by the negative aspects such as waste of time, occupation of cognitive and psychological capacity and the loss of useful study time, cellular dependence and anxiety due to the attractiveness and variety of mobile applications. They neglect when dealing with education and the like. In addition to the direct negative effects, excessive use of mobile phones on academic performance has indirect and mediated negative effects on students' psychological and social performance. The results of this study show that traumatic and excessive use of mobile phones is a potential risk factor for mental disorders in students and the emergence of such disorders, in turn, is an effective factor in reducing students' academic performance. Therefore, to reduce the negative effects of excessive use of cell phones on students' sleep and academic performance. In addition, it is recommended that sports, cultural, and recreational programs be encouraged to prevent student mobile phone addiction.

\section{Acknowledgment}

The authors thanks all the students and all those who supported them. This project is part of the results of a research project approved by the Student Research Committee of Kurdistan University of Medical Sciences. The researchers are grateful the deputy of research and technology of Kurdistan University of Medical Sciences for its financial support.

\section{Bibliography}

1. Esmaeilinasab M., et al. "The role of predictor of difficulty in emotion regulation and tolerance in students' addiction". Journal of Research Addicton 8.29 (2014): 50-63.

2. Xu J. "Research on the Relationship among Phone Addiction, Social Anxiety and Loneliness in High School Students". Open Journal of Social Sciences 5.6 (2017): 18.

3. Zanjani Z., et al. "The relationship of depression, distress tolerance and difficulty in emotional regulation with addiction to cell-phone use in students of Kashan University". Feyz Journal of Kashan University of Medical Sciences 22.4 (2018): 411-420.

4. Ahmdi MH and Elahi T. "The Relationship between Sensation Seeking and Using Additional Functions of Cell Phone in the Students of the University of Zanjan". Information and Communication Technology in Educational Sciences 4.15 (2014): 107-126.

Citation: Karo Servatyari., et al. "The Relationship between Mobile Phone Addiction and Depression and Hopelessness among High School Students in Divandareh city in 2018". Acta Scientific Medical Sciences 3.10 (2019): 58-64. 
5. Alhassan AA., et al. "The relationship between addiction to smartphone usage and depression among adults: a cross sectional study". BMC psychiatry 18.1 (2018): 148.

6. Harwood J., et al. "Constantly connected-The effects of smartdevices on mental health". Computers in Human Behavior 34 (2014): 267-272.

7. Lopez-Fernandez 0., et al. "Self-reported dependence on mobile phones in young adults: A European cross-cultural empirical survey". Journal of behavioral addictions 6.2 (2017): 168-177.

8. Yahyazadeh S., et al. "The prevalence of smart phone addiction among students in medical sciences universities in Tehran 2016". Advances in Nursing \& Midwifery 26.94 (2017): 1-10.

9. Liu Q.-Q., et al. "Mobile phone addiction and sleep quality among Chinese adolescents: a moderated mediation model". Computers in Human Behavior 72 (2017): 108-114.

10. Pedersen T. "Heavy cell phone use linked to depression, sleep problems in young people". Retrieved (2012).

11. Goswami V and Singh DR. "Impact of mobile phone addiction on adolescent's life: A literature review”. International journal of home science 2.1 (2016): 69-74.

12. Gao Y., et al. "How smartphone usage correlates with social anxiety and loneliness". Peer Journal 4(2016): e2197.

13. Organization WH. Depression and other common mental disorders: global health estimates. Retrieved from (2017).

14. Mohammad Beigi A., et al. "Depression symptoms prevalence general health statuse and its risk factors in dormitory students of Arak Universities in 2008". Arak Medical University Journal 12.3 (2009) 116-123.

15. Zarepoor F., et al. "Evaluation of depression and its relationship to exercise in women over 20 years". Journal of Shahid Sadoughi University of Medical Sciences 20.1 (2012): 64-72.

16. Amani F., et al. "The prevalence of depression among the students of Ardabil University of Medical Sciences" (2003).

17. Koplik EK and de Vito AJ. "Problems of freshmen: Comparison of classes of 1976 and 1986". Journal of College Student Person- nel (1986).

18. Mayes AN and McConatha J. "Surveying student needs: A means of evaluating student services". Journal of College Student Personnel 23.6 (1982): 473-476.

19. Morahan-Martin J and Schumacher P. "Incidence and correlates of pathological Internet use among college students". Computers in human behavior 16.2 (2000): 13-29.

20. Khazaie T., et al. "Prevalence of mobile dependency and adolescence aggression". Journal of Birjand University 19.4 (2013): 430-438.

21. Sevari K. "Construction and Validation of the Mobile Phone Addiction Questionnaire". Educational Measurement 4.15 (2014): 126-142.

22. Kaviani H and Mousavi A. "Psychometric properties of the Persian version of Beck Anxiety Inventory (BAI)". Tehran University Medical Journal TUMS Publications 66.2 (2008): 136-140.

23. Beck AT., et al. "The measurement of pessimism: the hopelessness scale". Journal of consulting and clinical psychology 42.6 (1974): 861.

24. Zargar Y., et al. "The relationship between personality traits (sensation seeking, assertiveness, psychological hardiness), the religious attitude and marital satisfaction with readiness for drug abuse". Journal of Education and Psychology Chamran University 1.3 (2008): 99-120.

25. Servatyari K., et al. "Frequency of psychological disorders symptoms and their effects on high school students in Divandareh city in 2018". Shenakht Journal of Psychology and Psychiatry 6.3 (2019): 71-82.

26. Višnjić, A., et al. "Relationship between the manner of mobile phone use and depression, anxiety, and stress in university students". International journal of environmental research and public health 15.4 (2018): 697.

27. Pawłowska B and Potembska E. "Gender and severity of symptoms of mobile phone addiction in Polish gymnasium, secondary school and university students". Current Problems of Psychiatry 12.4 (2011). 
28. Emelin V., et al. "Excessive use of internet, mobile phones and computers: the role of technology-related changes in needs and psychological boundaries". Procedia-social and behavioral sciences 86 (2013) 530-535.

29. Li J., et al. "Locus of control and cell phone use: Implications for sleep quality, academic performance, and subjective wellbeing". Computers in Human Behavior 52 (2015): 450-457.

Volume 3 Issue 10 October 2019

(C) All rights are reserved by Karo Servatyari., et al. 